\title{
Juan Pablo RONCONE. Hermano ciervo. Santiago: Libros del laurel, 2016, 126 pp.
}

Los ocho cuentos que componen Hermano ciervo, de Juan Pablo Roncone están cruzados por un halo de muerte común. El primero se titula precisamente "Muerte del canguro"; el segundo cuento "Niños" describe, entre otras cosas, las sesiones de espiritismo de un grupo de personas que invocan a sus hijos muertos; "El hijo de mi peluquero" trata de un sujeto al que le atropellan a su hijo enfermo y que planea, en son de venganza, la muerte de los hijos del conductor victimario; en "Gansos", se narra el episodio de un hijo que decide conocer a su padre moribundo, sin concretarlo; "La muerte de Raimundo" no requiere explicación; en "Cazador de patos" el cuento inicia informando que "[E]l padre de Cristóbal murió hace dos semanas" (p. 91); "Hermano ciervo" trata del suicidio del hermano homosexual del narrador y, finalmente, en "Hombres que caminan solos junto al mar", al narrador se le murió su hija Camila.

Los narradores de los ocho cuentos adoptan el rasgo común de un sujeto desencantado y desilusionado. Se trata principalmente de sujetos veinteañeros que viven su etapa universitaria, en carreras profesionales que no son de su gusto, con relaciones familiares precarias emocionalmente y que los empuja a cobijarse en relaciones extrafamiliares:

De un tiempo a esta parte tenía la costumbre de visitar grupos de todo tipo: sindicatos, conferencias de autoayuda, talleres literarios gratuitos, ciclos de cine, centros políticos para jóvenes o charlas para adictos. No me importaba mucho el tema o la gente, solo buscaba estar en algún lugar, rodeado de personas, y dejarme llevar por la voces de otros, por la compañía de otros" (pp. 21-22).

Roncone utiliza un lenguaje seco y directo. Minimiza los recursos retóricos para ofrecer una narración casi telegráfica de los hechos y emociones. Compone los relatos como "historias dispersas y fragmentarias, como suelen ser las buenas y verdaderas historias" nos señala el autor en un recurso metatextual en el cuento "La muerte de Raimundo" (p. 83). Los finales son inesperados y dejan la sensación de un relato inacabado que transfieren una inquietud que perturba, como si hubiese algo pendiente que el narrador no haya querido decir y que puede ser incluso peor a lo ya descrito.

Arthur Schopenhauer, en su oposición al optimismo y al triunfalismo histórico hegeliano imperante en su época, propone desengañarse, por irrisoria, de toda utopía de salvación colectiva para la humanidad. Se trata de un pensamiento fundamental para comprender a Nietzsche, Freud y Wittgenstein a pesar de las severas críticas de Lukács a sus planteamientos. "Exigir la inmortalidad del individuo (nos dice Schopenhauer) es querer perpetuar un error hasta el infinito. En el fondo, toda individualidad es un error especial, una equivocación, algo que no debiera existir" (pp. 108-109). En otras palabras, la vida ofrece el espectáculo absurdo de una voluntad de vida que continuamente se devora a sí misma. 


\section{Reseñas}

Si la desilusión acompaña a las reflexiones de todos los narradores de Roncone, se podrían comprender desde la perspectiva del pensamiento de Schopenhauer. La apatía de ciertos personajes no es sino el corolario de un dolor que sobrepasa toda comprensión. De ahí que Roncone utiliza recurrentemente la muerte de los hijos, ya que esta fatalidad podría considerarse como uno de los dolores más severos y profundos a los que puede someterse un ser humano. En "Gansos" se lee: "Lourdes y yo fuimos convirtiéndonos en confesores mutuos de nuestras pequeñas miserias" (p. 59). Para Schopenhauer, el dolor es lo auténticamente positivo y el placer no es sino la ausencia de dolor, por lo que, estamos condenados no a muerte sino a vida. La vida, para dicho pensador no es realmente dolorosa sino absurda y la predisposición de los personajes construidos por Roncone son precisamente la de unas subjetividades que quedan inertes ante la sinrazón de la existencia, abatidos pasajeramente ante el espejismo de la felicidad. Se podría decir que cunde en los relatos de Roncone una cierta estética de la indiferencia.

Todo deseo satisfecho se caracteriza por ser una sensación efímera y que por esa razón va acompañado por la desilusión. Jacques Lacan, en su concepto de "pulsión de muerte", nos complementa: "el goce se presenta no pura y simplemente como la satisfacción de una necesidad, sino como la satisfacción de una pulsión. (...) Allí también se registra (...) la destrucción" (p. 253). Si a la estética de la indiferencia en Roncone la agregamos la pulsión de muerte lacaniana, podremos interpretar que las muertes que rodean a los personajes de sus cuentos se pueden sustentar en una voluntad de destrucción que genera un principio de creación o la voluntad de recomenzar que sucede a toda destrucción.

Hermano ciervo es una obra que ha provocado disímiles reacciones críticas. Es un texto que no ha sido objeto de estudios académicos y sus reseñas son dispares. Van desde el rechazo explícito como "un aburrido ejercicio de literatura neoliberal" o como "el plagio latero de libros muy malos" (Cristián Verscheure en biobiochile.cl), hasta comentarios más entusiastas que ven en Roncone "una oportunidad de redención" (Francisco Díaz en Intemperie). Este último comentario puede leerse en afinidad con la hipótesis de lectura ceñida al pensamiento de Schopenhauer y Lacan.

Para Alberto Fuguet, Hermano ciervo es "un libro indie, alternativo, marginal, que en apariencia parece ser extremadamente literario o intelectual". Sostiene, además, que se trata de "una colección de ocho cuentos que, quizá ordenados de otra manera, o con tres alteraciones, se vuelve una novela feroz" (cinépata.com).

Si nos quedamos con la idea de una novela feroz, propongo leer a Hermano ciervo desde el anonadamiento. Junto con la estética de la indiferencia que conecta la tonalidad de Roncone con el pensamiento de Schopenhauer y el principio de destrucción que lo vincula a Lacan, se percibe en esta obra el desengaño de una ilusión que permite leerlo bajo el prisma del pensamiento contemporáneo de E.M. Cioran, emparentado en algunos aspectos con Schopenhauer. El desengaño de la ilusión, en Cioran, permite al sujeto creer que es posible alcanzar un estado de desilusión completo: 
"[M]i facultad de decepción sobrepasa el entendimiento" (p. 11), sentencia Cioran. En otro parágrafo de su obra Del inconveniente de haber nacido, señala:

No corremos hacia la muerte; huimos de la catástrofe del nacimiento. Nos debatimos como sobrevivientes que tratan de olvidarlo. El miedo a la muerte no es sino la proyección hacia el futuro de otro miedo que se remonta a nuestro primer momento (p. 8).

Es posible que en Hermano ciervo nos encontremos ante una voluntad de no desear que es en sí una forma de deseo, una peligrosa y solapada forma de deseo, ya que está mejor disfrazada que el resto. Con ello nos acercamos a una fatalidad neurótica. El rodeo de la muerte como la circunvalación temática que impregna los cuentos de Roncone permite entender ese deseo de no desear en ciertos finales insólitos como el de "Niños", en cuyo diálogo mental, el narrador piensa toda una proyección amatoria con 'la moderadora' que obviamente no se concreta por su falta de expresión; o en "Gansos" cuando al final el narrador decide dejar a Lourdes a pesar de la felicidad que había obtenido y piensa: "[S]entí en el aire la tristeza de Lourdes: una línea que dividía el espacio. Quise decirle que no quería irme, que quería quedarme con ellos. Pero no fui capaz de hacerlo" (69); o finalmente, en el último cuento "Hombres que caminan solos junto al mar", cuando en ese diálogo del narrador con su pareja Antonieta este confiesa que debiese haber hecho cosas que finalmente no hizo y que son irrevocables. Se imaginan haber traído a Camila, la hija del narrador, a la playa antes de su muerte:

- Sí, deberíamos haberla traído.

- Hubiese sido una buena idea -dije-, y pensé en la casa incendiada de Hernández, y me arrepentí por no haberlo acompañado a comprar empanadas. Hubiese sido una buena idea (p. 126).

https://doi.org/10.32735/S0718-2201201900048631

Sergio Pizarro Roberts

Universidad de Playa Ancha (Chile) sergioto.pizarro@gmail.com 